\title{
Long non-coding RNA H19 correlates with unfavorable prognosis and promotes cell migration and invasion in ovarian cancer
}

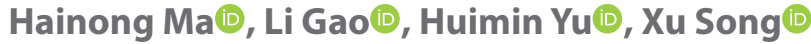 \\ Hwamei Hospital, University of Chinese Academy of Sciences, Ning Bo, China
}

\begin{abstract}
Objectives: The purpose of this study is to investigate the expression pattern of IncRNA H19 in OC tissues and to detect the ability of $\mathrm{H} 19$ to influence $\mathrm{OC}$ cell migration and invasion in vitro.

Material and methods: We quantified the levels of $\mathrm{H} 19$ within the obtained cancerous and adjacent noncancerous tissues from $258 \mathrm{OC}$ patients. $\mathrm{H} 19$ association with patient progression-free survival (PFS) was analyzed by a Kaplan-Meier plot. Expression levels of $\mathrm{H} 19$ were reduced by small interfering RNA transfection against $\mathrm{H} 19$ or restored by a $\mathrm{H} 19$ overexpression plasmid transfection in OC cells. $\mathrm{H} 19$ effects on OC cell migration and invasion in vitro were evaluated using wound-healing assay and transwell invasion assay. Wound healing assay and transwell invasion assay were used to evaluate the effects of $\mathrm{H} 19$ on $\mathrm{OC}$ cell migration and invasion in vitro.
\end{abstract}

Results : H19 is upregulated remarkably in primary OC tissues and human OC cell lines (OVCAR3, SKOV3, A2780, and Caov-3). We found that the median PFS was longer in patients with lower levels of $\mathrm{H} 19$ than in those with high levels, suggesting that overexpres- sion of $\mathrm{H} 19$ was linked to poor prognosis in OC patients. Intriguingly, the depletion of $\mathrm{H} 19$ expression induced by small interfering RNA inhibited the capability of migration and invasion of OC cell lines. Restoration of $\mathrm{H} 19$ in OC cell lines significantly increased cell migration and invasion.

Conclusions: The key finding of the present study suggests that overexpression of $\mathrm{H} 19$ may be associated with an unfavorable prognosis for $\mathrm{OC}$ and is likely to be a possible contributory force involved in OC cell migration and invasion. $\mathrm{H} 19$ may provide a new and attractive target for future prognostic and therapeutic intervention of OC patients.

Key words: ovarian cancer; long non-coding RNA; H19; prognosis; migration

Ginekologia Polska 2022; 93, 1:1-6

\section{INTRODUCTION}

The continuing increase in the incidence and prevalence of ovarian cancer (OC) is a cause for concern [1]. Up until now, OC represented the second most common gynecological malignancies, accounting for $5 \%$ of all cancers in females [2]. On an annual basis, an estimated 220,000 newly diagnosed OC cases worldwide [3]. Due to its late presentation and often being diagnosed at an advanced stage, most patients succumb to recurrence and wide metastasis, explaining the high mortality rate [4]. OC is heterogeneous in nature and encompasses a collection of distinct histologic types, all with characteristic differences, which is one of the major obstacles to improvement in this disease [5]. Early stage $\mathrm{OC}$ symptoms of peritoneal metastasis are generally nonspecific, which subsequently allows for frequent misdiagnoses as well as underdiagnoses. Expression patterns of a recently identified biomarker family, long non-coding RNA (IncRNA), seem to be characteristic of tumor type and developmental origin, including OC [6, 7].

Understanding of expression pattern and imprinting of $\mathrm{H} 19$ has progressed considerably in recent years. The function of $\mathrm{H} 19$ in cancers remains to be elucidated due to its dual roles acting either as a tumor suppressor or an oncogene. In a recent study, $\mathrm{H} 19$ is shown to inhibit cancer progression $[8,9]$. However, increasing evidence showed that $\mathrm{H} 19$ expression was increased in several cancers such as breast cancer, lung cancer, gastric cancer, and bladder cancer [10-13], highlighting its oncogenic properties. In- 
triguingly, several gain- or loss-of-function studies demonstrated that $\mathrm{H} 19$ knockdown suppressed cell migration and invasion in clear cell renal carcinoma and glioma [14, 15]. Few data support the functional role of $\mathrm{H} 19$ in OC, and only a study reported by Zhu et al. proposed the contributory effect of $\mathrm{H} 19$ in OC [16]. However, measurement of $\mathrm{H} 19$ in 70 pairs of $\mathrm{OC}$ tissue samples and normal controls may limit the validity of results.

To investigate the expression and functional role of $\mathrm{H} 19$ in human ovarian cancer, in this study we quantified the levels of $\mathrm{H} 19$ within the obtained cancerous and adjacent noncancerous tissues from OC patients. Progression-free survival (PFS) was calculated by following up with the patients. In addition, functional assays were applied in OC cells. Our research may provide evidence for the diagnosis and treatment of ovarian cancer.

\section{MATERIAL AND METHODS}

\section{Study subjects}

We collected cancerous and adjacent noncancerous tissues from 258 patients with $\mathrm{OC}$ who were admitted into our hospital between January 2010 and January 2014. These patients had a mean age of $48.5 \pm 6.3$ (ranging from 29 to 68 years old). The inclusion criteria for patient enrollment: (1) an ovary biopsy with pathological and imaging diagnosis of OC; (2) an initial treatment in our hospital for OC; (3) no standard therapies, such as chemotherapy, surgery, or radiation therapy; (4) no previous history of the malignant tumors; (5) no distant metastases or second primary tumor. The study protocol was approved by the Institutional Ethics Committees at our hospital, and signed written informed consent was received from all patients prior to enrollment.

\section{Follow-up}

The follow-up was scheduled at discharge, ranging from 3 to 36 months and consisting of a telephone interview, a medical record review, or a hospital visit. The follow-up period ended on December 2016. Among 258 cases, 6 cases were censored. A follow-up rate of $93.0 \%$ was achieved. The primary endpoint was progression-free survival (PFS) was defined as the time from diagnosis to either disease progression or relapse, or to death as a result of any cause.

\section{Cell preparation}

Human normal ovarian surface epithelial cell lines were purchased from Shanghai Huiying Bio-technology Co., Ltd., China and human OC cell lines, OVCAR3, SKOV3, A2780, and Caov-3, from Cell Bank of Chinese Academy of Sciences, Shanghai, China. SKOV3 cells were cultured with McCoy's 5A Medium Modified (Sigma, St. Louis, MO, USA), in addition,RPMI-1640 medium (Gibco Company, Grand Island,
NY, USA) for OVCAR3 and A2780 cells, and DMEM-H (Dulbecco's Modified Eagle's Medium, High Glucose; Hyclone Laboratories, Logan, Utah, USA) for Caov-3 cells. All of the media were supplemented with $10 \%$ fetal bovine serum (FBS, Gibco Company, Grand Island, NY, USA), and all cells were incubated with $5 \% \mathrm{CO}_{2}$ at $37^{\circ} \mathrm{C}$. In order to evaluate the regulatory effects of $\mathrm{H} 19$ on $\mathrm{OC}$ cells, SKOV3 cells showing the highest expression level of $\mathrm{H} 19$ were treated by small interfering RNA (siRNA) against $\mathrm{H} 19$ and a $\mathrm{H} 19$ overexpression plasmid, respectively. An ineffective scramble of siRNA, a siRNA against $\mathrm{H} 19$, and $\mathrm{H} 19$ overexpression plasmid was purchased from Shanghai GenePharma Co., Ltd. (Shanghai, China). The Lipofectamine 2000 (Invitrogen Corp., Carlsbad, (A, USA) was used to transfection operations according to the manufacturer's instructions.

\section{Reverse transcription quantitative polymerase chain reaction ( $R T-q P C R$ )}

Total RNA from tissues was isolated by TRIzol kits (Invitrogen, Carlsbad, CA, USA). High-molecular-weight RNA was identified on a denaturing formaldehyde gel, then I $\mu \mathrm{g}$ of RNA was reversely transcripted into cDNA using AMV-reverse transcriptase. Primers were obtained from Invitrogen Inc., Carlsbad, CA, USA (Tab. 1). GAPDH was used as a loading control. The PCR cycling reaction conditions: pre-denaturation at $94^{\circ} \mathrm{C}$ for $5 \mathrm{~min}$, followed by 40 cycles of denaturation at $94^{\circ} \mathrm{C}$ for $40 \mathrm{~s}$, annealing at $60^{\circ} \mathrm{C}$ for $40 \mathrm{~s}$ and extension at $72^{\circ} \mathrm{C}$ for $1 \mathrm{~min}$, followed by a final extension at $72^{\circ} \mathrm{C}$ for $10 \mathrm{~min}$. PCR products were then subject to agarose gel electrophoresis and analyzed by Opticon Monitor ${ }^{\mathrm{TM}}$ version 3.0 software (Bio-Rad, Inc., Hercules, CA, USA). The Opticon monitor software (MJ Research, San Francisco, CA, USA) was used to set the cycle threshold or $\mathrm{Ct}$ line manually. Data were analyzed by $2^{-\Delta \Delta \mathrm{Ct}}$ method. $\Delta \mathrm{Ct}=\mathrm{Ct}$ (target gene)-Ct (loading control), $\Delta \Delta \mathrm{Ct}=\Delta \mathrm{Ct}$ (experimental group) $-\Delta \mathrm{Ct}$ (control group). The experiment was repeated three times independently, with the average obtained.

\section{Transwell assay}

Forty eight hours after transfection, $1 \times 10^{5}$ cells were counted and inoculated in Matrigel-coated ( $80 \mu$ l of at a ratio of 1:8) transwell chambers containing $100 \mu \mathrm{l}$ serum-free DMEM medium. The Matrigel and cells that remained on the upper side were wiped off following 24 hours incubation. Then, the passed cells were fixed in $4 \%$ paraformaldehyde for $15 \mathrm{~min}$ and subsequently stained with $0.2 \%$ crystal violet for $10 \mathrm{~min}$. Lastly, an inverted light microscope (Olympus IX70, Tokyo, Japan, at $\times 200$ magnification) was applied to count the number of invading cells in five predetermined fields to evaluate cell invasion. All experiments were independently performed at least three times. 


\begin{tabular}{|c|c|}
\hline Gene & Sequences \\
\hline \multirow{2}{*}{ H19 } & F: 5'-GTCCGGCCTTCCTGAACACCTT-3' \\
\hline & R: 5'-GCTTCACCTTCCAGAGCCGAT-3' \\
\hline \multirow{2}{*}{ GAPDH } & F: 5'-GACAACTTTGGCArCGTGGA-3' \\
\hline & R: 5'-ATGCAGGGATGATGTTCTGG-3' \\
\hline
\end{tabular}

\section{Scratch test}

On the back of the 6-well plate, use a marker pen to scratch an even with an interval width of $0.8 \mathrm{~cm}$. Each well was required to be crossed by more than five lines and added with $5 \times 10^{5}$ wells. When the cells grew to $100 \%$, a uniform scratch was made in the center of the well using a sterile micropipette tip, followed by washing with phosphate-buffered saline. After 58 hours incubation with $5 \% \mathrm{CO}_{2}$ at $37^{\circ} \mathrm{C}$, the wound healing was photographed for the record. The rate of cell migration was assessed by the wound closure assay. All experiment was also independently performed at least three times.

\section{Statistical analysis}

Statistical analysis was done using SPSS software (IBM SPSS Statistics, version 21.0, Armonk, NY, USA). Measurement data were expressed as the mean \pm standard deviation (SD); Fisher's least significant difference (LSD) was conducted for pairwise comparisons, one-way analysis of variance (ANOVA) test for comparisons among multiple groups, and $t$-test for comparisons between two groups when demonstrating normal distribution. The association with survival was analyzed initially by Kaplan-Meier plot and log-rank test. Differences were accepted as significant if $\mathrm{p}$-values less than 0.05 .

\section{RESULTS}

\section{Increased expression levels of H19 in OC primary} tissues

Firstly, in order to evaluate the expression pattern of $\mathrm{H} 19$ in OC, we quantified the expression levels of $\mathrm{H} 19$ within the obtained cancerous and adjacent noncancerous tissues from 258 OC patients using RT-qPCR. We found that the expression levels of $\mathrm{H} 19$ in cancer tissues $(5.82 \pm 0.67)$ were higher than those in adjacent noncancerous tissues $(2.46 \pm 0.29, P<0.01)$.

\section{Increased expression levels of H19 associated with poor survival of $\mathrm{OC}$ patients}

Next, we classified 258 OC patients into low- and high-level groups in terms of expression levels of $\mathrm{H} 19$ in OC primary tissues to evaluate the association between

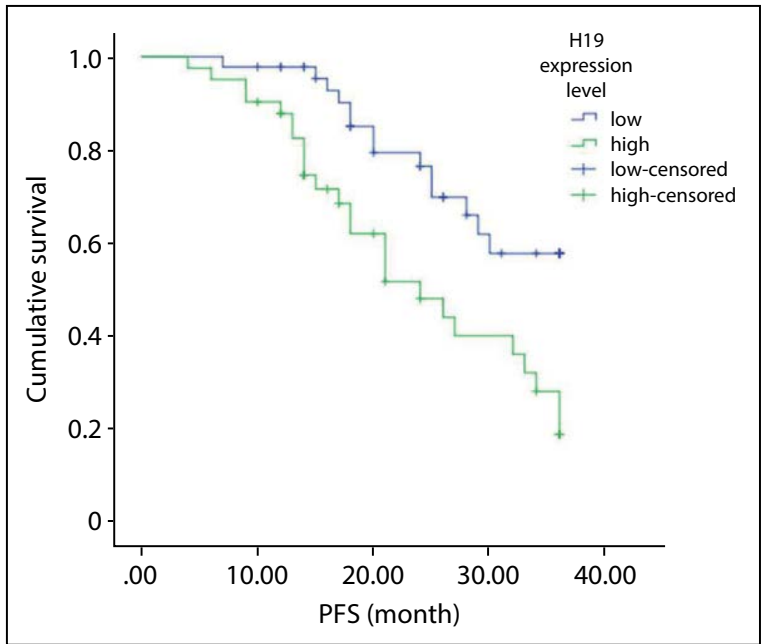

Figure 1. The Kaplan-Meier plot showed that increased expression levels of $\mathrm{H} 19$ are associated with poor survival of OC patients

the $\mathrm{H} 19$ expression levels and patient survival. We regarded patient PFS as the end point event. The Kaplan Meier survival analysis (Fig. 1) showed the median PFS was longer in OC tissues with low expression levels of $\mathrm{H} 19$ than in those with high expression levels (30.00 months vs. 24 months, $P<0.01)$. The data reveal that increased expression levels of $\mathrm{H} 19$ associated with poor survival of OC patients.

\section{Increased expression levels of H19 in OC cell lines}

In this study, we chose OC cell lines that have been widely used in $\mathrm{OC}$ research, especially in functional studies. We examined the expression levels of $\mathrm{H} 19$ in OVCAR3, SKOV3, A2780, and Caov-3 cell lines by RT-qPCR. The result showed that $\mathrm{H} 19$ was increased in these four $\mathrm{OC}$ cell lines $(P<0.05$, Fig. 2$)$ in which SKOV3 cell lines were highest.

\section{Silencing or restoring $\mathrm{H} 19$ in OC cells}

Furthermore, we treated SKOV3 cells with an ineffective scramble of siRNA, siRNA against $\mathrm{H} 19$, and a $\mathrm{H} 19$ overexpression plasmid, respectively. We quantified the expression levels of $\mathrm{H} 19$ in SKOV3 cells after different treatments by RT-qPCR. Indeed, $\mathrm{H} 19$ expression was restored by $\mathrm{H} 19$ overexpression plasmids, while $\mathrm{H} 19$ expression was suppressed by siRNA against $\mathrm{H} 19(P<0.05)$. There was no significant difference in $\mathrm{H} 19$ expression levels when untreated SKOV3 cells were compared to SKOV3 cells treated with ineffective scramble of siRNA. The data are shown in Figure 3.

\section{The contributory effects of $\mathrm{H} 19$ on OC cell invasion and migration in vitro}

To know the function of $\mathrm{H} 19$ in OC, we tested the effects of $\mathrm{H} 19$ on cell invasion and migration in vitro by transwell invasion assay and wound-healingassay. To determine the 


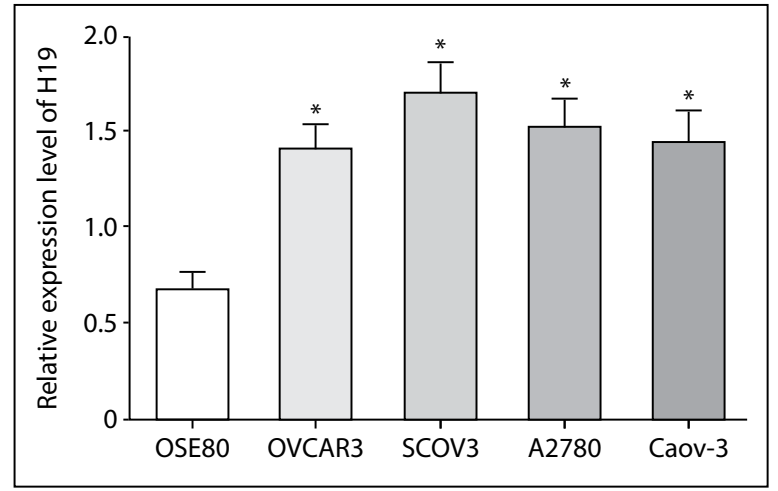

Figure 2. Increased expression levels of $\mathrm{H} 19$ in OC cell lines, determined by RT-qPCR. Compared with IOSE80 cells, OVCAR3, SKOV3, A2780, and Caov-3 cells showed higher expression levels of $\mathrm{H} 19$ ( $\left.{ }^{*}-P<0.05\right)$. Among these four OC cell lines, SKOV3 cell lines exhibited the highest expression levels of $\mathrm{H} 19$

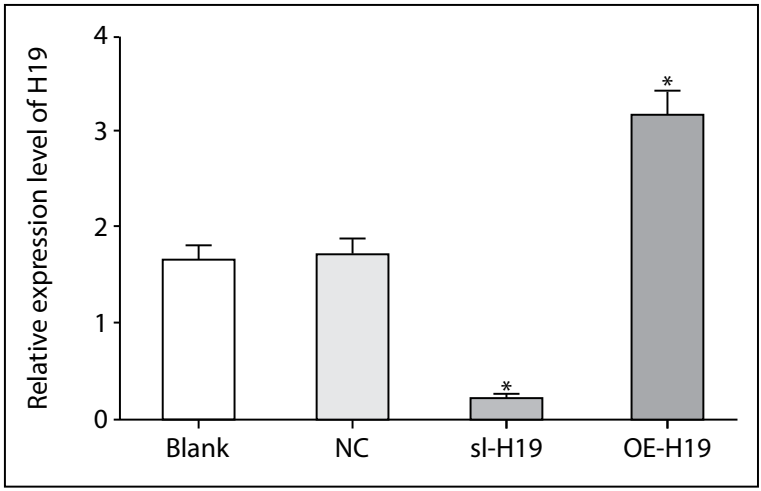

Figure 3. $\mathrm{H} 19$ expression was suppressed or restored in SKOV3 cells, verified by RT-qPCR; * $-P<0.05$ compared with untreated SKOV3 cells

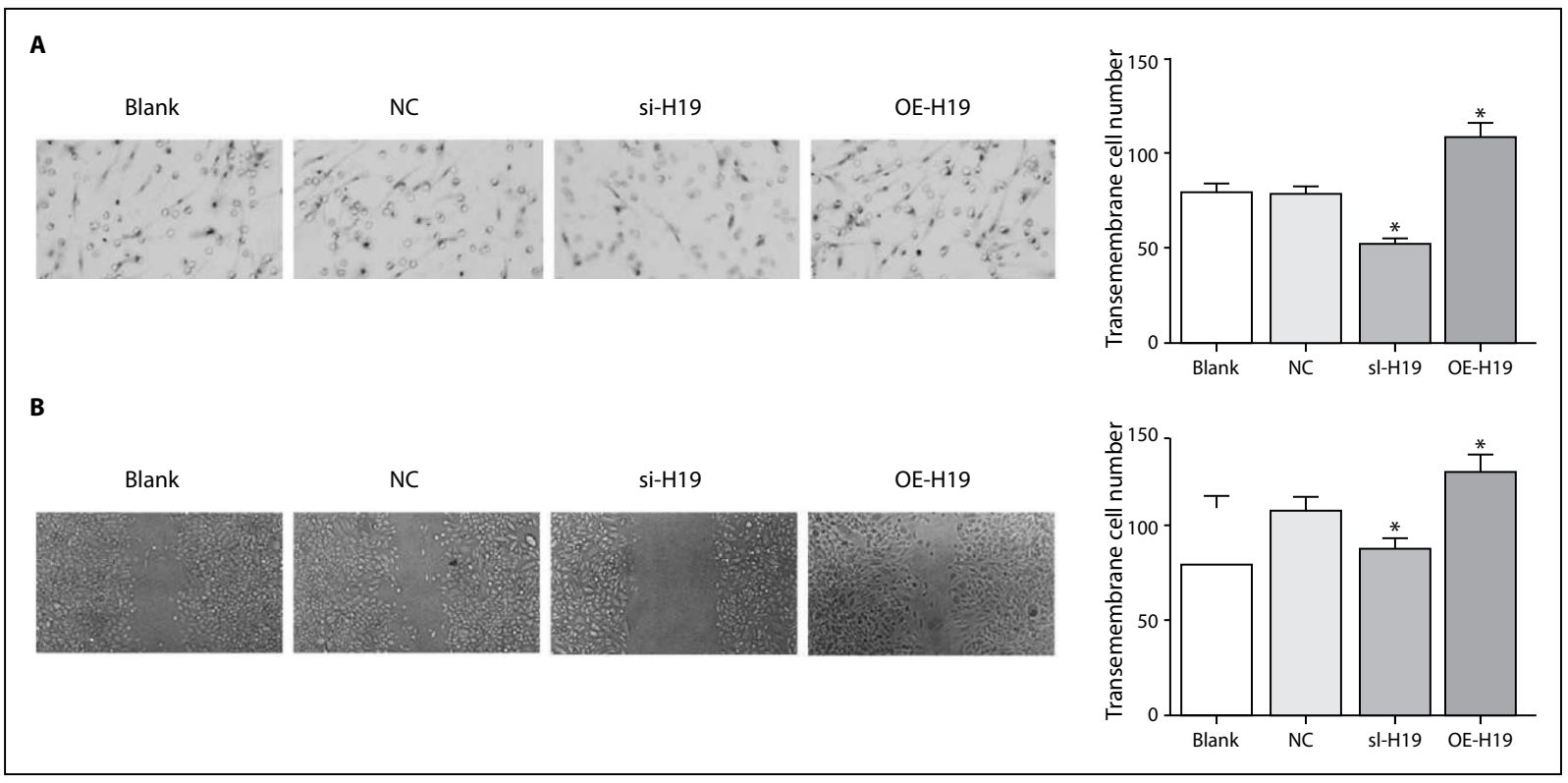

Figure 4. $\mathrm{H} 19$ could promote $\mathrm{OC}$ cell invasion and migration; A. wound-healing assay was used to determine the effect of $\mathrm{H} 19$ on the invasion potential of SKOV3 cells $(\times 200)$; B. transwell invasion assay was used to determine the impact of H19 on migration potential of SKOV3 cells $(\times 200)$; * $-P<0.05$ compared with untreated SKOV3 cells

effect of $\mathrm{H} 19$ on the invasion potential of SKOV3 cells, we first carried out Matrigel invasion assays (Fig. 4A). After harvesting for $48 \mathrm{~h}$, we found fewer SKOV3 cells treated with siRNA against $\mathrm{H} 19$ passed through Matrigel, but more SKOV 3 cells treated with $\mathrm{H} 19$ overexpression plasmids passed through Matrigel $(P<0.05)$. An ineffective scramble of siRNA did not significantly affect the invasion of SKOV3 cells $(P>0.05)$. Next, wound-healing assay was used to determine the effect of $\mathrm{H} 19$ on the migration potential of SKOV3 cells (Fig. 4B). After harvesting for 48 h, we found SKOV3 cells treated with siRNA against $\mathrm{H} 19$ were distinctively less migrated, but SKOV3 cells treated with $\mathrm{H} 19$ overexpression plasmids healed the wound area faster $(P<0.05)$. An ineffec- tive scramble of siRNA did not significantly affect the migration of SKOV3 cells $(P>0.05)$. These findings indicated that $\mathrm{H} 19$ could promote $\mathrm{OC}$ cell invasion and migration in vitro.

\section{DISCUSSION}

LncRNAs are becoming new candidates for diagnosing cancer disease, explaining the mechanism of the pathogenesis and development of malignant tumors, predicting prognosis and treating disease as targets in recent years [17]. In the present study, we demonstrate the role of $\mathrm{H} 19$ as an oncogene in OC. Significantly, $\mathrm{H} 19$ was found to be increased in primary $\mathrm{OC}$ tissues and cell lines compared with adjacent normal tissues and normal cell lines, 
and overexpression of $\mathrm{H} 19$ was linked to poor prognosis in OC patients. In addition, in order to detect the ability of $\mathrm{H} 19$ to influence $\mathrm{OC}$ cell migration and invasion in vitro, the expression levels of $\mathrm{H} 19$ were reduced by small interfering RNA transfection against $\mathrm{H} 19$, or restored by a $\mathrm{H} 19$ overexpression plasmid transfection in OC cells. The contributory effects of this IncRNA on cell migration and invasion indicate that $\mathrm{H} 19$ promotes tumorigenesis in $\mathrm{OC}$.

Recently, $\mathrm{H} 19$ is highlighted for its association and involvement with many cancers, as it plays an important role in regulating the expression of many genes that are essentials for numerous cellular processes [18]. Yang et al. reported that ectopic expression of $\mathrm{H} 19$ increased cell proliferation, and cell apoptosis was induced in gastric cancer cell lines while siRNA-mediated down-regulation of $\mathrm{H} 19$ [12]. They also found $\mathrm{H} 19$ affected the activity of $\mathrm{p} 53$, and that this effect was leading to partial p53 inactivation. Suppression of $\mathrm{H} 19$ induces invasion of serous borderline ovarian tumor cells via reducing $\mathrm{PI} 3 \mathrm{~K} / \mathrm{Akt}$-mediated inhibition $\mathrm{E}$-cadherin [19]. He et al. reported the mechanism that overexpression of $\mathrm{H} 19$ was sufficient to increase the expression of E2F1 by which $\mathrm{H} 19$ promotes $\mathrm{OC}$ migration and invasion [14]. E2F1 exerts an anti-proliferative effect in OC cells, becoming a target for preventing OC [20]. Luo and his team found that upregulated $\mathrm{H} 19$ promotes bladder cancer cell migration associating with enhancer of zeste homolog $2(\mathrm{EZH} 2)$, and that this association was leading to $\mathrm{Wnt} / \beta$ catenin activation and subsequent inhibition of E-cadherin [13]. EZH2 is found to be upregulated in malignant tumors and is involved in metastasis, including $\mathrm{OC}$, and overexpression of EZH2 facilitates OC cell invasion and migration [21]. An unexpected mode of action of $\mathrm{H} 19$ can antagonize the let-7 family of microRNAs [22]. An increase of microRNA let-7i expression induces $O C$ cell apoptosis, which is the mechanism of propofol, can effectively inhibit proliferation and induce apoptosis in OC cells [23]. Inhibited let-7i expression remarkably reduced the resistance of OC cells to the chemotherapy drug, and decreased let-7i expression was associated with the shorter PFS of OC patients, which may explain the fact that overexpression of $\mathrm{H} 19$ was linked to poor prognosis in OC patients [24]. A high $\mathrm{H} 19$ expression contributes to poor overall survival and can be served as an independent predictor of the overall survival of gastric cancer patients [25], which may provide evidence for the prognostic role of $\mathrm{H} 19$ in OC, as reflected in our study.

\section{CONCLUSIONS}

Based on the key findings obtained from our study, we believe that $\mathrm{H} 19$ could potentially act as atherapeutic target. The reasons were as follows: (1) $\mathrm{H} 19$ expression levels are significantly increased in tissues and cell lines of $\mathrm{OC}$; (2) H19 in relation to OC prognosis; (3) inhibiting $\mathrm{H} 19$ suppresses $\mathrm{OC}$ cell migration and invasion.

Taken together, our findings indicate that $\mathrm{H} 19$ plays a vital role in the development and progression of OC. The development of downregulation of this oncogenic IncRNAs based on H19-based therapeutic strategies may provide new and promising alternative therapeutics for future OC treatment. However, a larger sample size and longer follow-up period are required to confirm the correlation between $\mathrm{H} 19$ expression level and overall 5-year survival rate of OC patients. Meanwhile, more attention should be paid to exploring the mechanism of $\mathrm{H} 19$ and its interaction with oncogenes, and a new target should be discovered to cope with the highly migratory and invasive OC.

\section{Ethical approval}

The study protocol was approved by the Institutional Ethics Committees of Haimei Hospital, University Of Chinese Academy Of Sciences, and signed written informed consent was received from all patients prior to enrollment.

\section{Consent for publication}

Informed consent was obtained from all individual participants included in the study.

\section{Availability of data and material}

The datasets used or analysed during the current study are available from the corresponding author on reasonable request.

\section{Conflict of interests}

None.

\section{Funding}

This study was supported by Supported by Research Foundation of HwaMei Hospital, University of Chinese Academy of Sciences, China (Grant No. 2020HMZD15).

\section{Acknowledgements}

We would like to give our sincere gratitude to the reviewers for their comments.

\section{REFERENCES}

1. Coburn SB, Bray F, Sherman ME, et al. International patterns and trends in ovarian cancer incidence, overall and by histologic subtype. International Journal of Cancer. 2017; 140(11): 2451-2460, doi: 10.1002/ijc.30676.

2. Cybulski M, Jeleniewicz W, Nowakowski A, et al. Cyclin I mRNA expression correlates with kinase insert domain receptor expression in human epithelial ovarian cancer. Anticancer Res. 2015; 35(2): 1115-1119, indexed in Pubmed: 25667501.

3. Zayed AA, Mandrekar SJ, Haluska P. Molecular and clinical implementations of ovarian cancer mouse avatar models. Chin Clin Oncol. 2015; 4(3): 30, doi: 10.3978/j.issn.2304-3865.2015.04.01, indexed in Pubmed: 26408297. 
4. Rattan R, Graham RP, Maguire JL, et al. Metformin suppresses ovarian cancer growth and metastasis with enhancement of cisplatin cytotoxicity in vivo. Neoplasia. 2011; 13(5): 483-491, doi: 10.1593/neo.11148, indexed in Pubmed: 21532889.

5. Tian $Y$, Yao Z, Roden RBS, et al. Identification of glycoproteins associated with different histological subtypes of ovarian tumors using quantitative glycoproteomics. Proteomics. 2011; 11(24): 4677-4687, doi: 10.1002/pmic.201000811, indexed in Pubmed: 22113853.

6. Zou A, Liu R, Wu X. Long non-coding RNA MALAT1 is up-regulated in ovarian cancer tissue and promotes SK-OV-3 cell proliferation and invasion. Neoplasma. 2016; 63(6): 865-872, doi: 10.4149/neo_2016_605, indexed in Pubmed: 27565324.

7. Fu Y, Biglia N, Wang Z, et al. Long non-coding RNAs, ASAP1-IT1, FAM215A, and LINC00472, in epithelial ovarian cancer. Gynecol Oncol. 2016; 143(3): 642-649, doi: 10.1016/j.ygyno.2016.09.021, indexed in Pubmed: 27667152.

8. Zhang A, Shang W, Nie Q, et al. Long non-coding RNA H19 suppresses retinoblastoma progression via counteracting miR-17-92 cluster. J Cell Biochem. ; 119(4): 3497-3509, indexed in Pubmed: 29143996.

9. Zhu M, Chen Q, Liu X, et al. IncRNA H19/miR-675 axis represses prostate cancer metastasis by targeting TGFBI. FEBS J. 2014; 281(16): 3766-3775, doi: 10.1111/febs.12902, indexed in Pubmed: 24988946.

10. Berteaux N, Lottin S, Monté D, et al. H19 mRNA-like noncoding RNA promotes breast cancer cell proliferation through positive control by E2F1. J Biol Chem. 2005; 280(33): 29625-29636, doi: 10.1074/jbc.M504033200, indexed in Pubmed: 15985428.

11. Zhang Q, Li X, Li X, et al. LncRNA H19 promotes epithelial-mesenchymal transition (EMT) by targeting miR-484 in human lung cancer cells. J Cell Biochem. 2018; 119(4): 4447-4457, indexed in Pubmed: 29219208.

12. Yang $\mathrm{F}$, Bi J, Xue X, et al. Up-regulated long non-coding RNA H19 contributes to proliferation of gastric cancer cells. FEBS J. 2012; 279(17): 3159-3165, doi: 10.1111/j.1742-4658.2012.08694.x, indexed in Pubmed: 22776265.

13. Luo M, Li Z, Wang W, et al. Long non-coding RNA H19 increases bladder cancer metastasis by associating with $\mathrm{EZH} 2$ and inhibiting E-cadherin expression. Cancer Lett. 2013; 333(2): 213-221, doi: 10.1016/j.canlet.2013.01.033, indexed in Pubmed: 23354591.

14. He H, Wang $\mathrm{N}$, Yi X, et al. Long non-coding RNA H19 regulates E2F1 expression by competitively sponging endogenous miR-29a-3p in clear cell renal cell carcinoma. Cell Biosci. 2017; 7: 65, doi: 10.1186/s13578017-0193-Z, indexed in Pubmed: 29214011.

15. Shi Y, Wang Y, Luan W, et al. Long non-coding RNA H19 promotes glioma cell invasion by deriving miR-675. PLoS One. 2014; 9(1): e86295, doi: 10.1371/journal.pone.0086295, indexed in Pubmed: 24466011.

16. Zhu Z, Song L, He J, et al. Ectopic expressed long non-coding RNA H19 contributes to malignant cell behavior of ovarian cancer. Int J Clin Exp Pathol. 2015; 8(9): 10082-10091, indexed in Pubmed: 26617715.

17. Worku T, Bhattarai $D$, Ayers $D$, et al. Long non-coding RNAs: the new horizon of gene regulation in ovarian cancer. Cell Physiol Biochem. 2017; 44(3): 948-966, doi: 10.1159/000485395, indexed in Pubmed: 29179183.

18. Zhou X, Ye F, Yin C, et al. The interaction between MiR-141 and IncR$\mathrm{NA}-\mathrm{H} 19$ in regulating cell proliferation and migration in gastric cancer. Cell Physiol Biochem. 2015; 36(4): 1440-1452, doi: 10.1159/000430309, indexed in Pubmed: 26160158.

19. Cheng JC, Auersperg N, Leung PCK. Inhibition of p53 induces invasion of serous borderline ovarian tumor cells by accentuating PI3K/Akt-mediated suppression of E-cadherin. Oncogene. 2011; 30(9): 1020-1031, doi: 10.1038/onc.2010.486, indexed in Pubmed: 20972462.

20. Valle BL, D'Souza T, Becker KG, et al. Non-steroidal anti-inflammatory drugs decrease E2F1 expression and inhibit cell growth in ovarian cancer cells. PLoS One. 2013; 8(4): e61836, doi: 10.1371/journal.pone.0061836, indexed in Pubmed: 23637916.

21. Yi X, Guo J, Guo J, et al. EZH2-mediated epigenetic silencing of TIMP2 promotes ovarian cancer migration and invasion. Sci Rep. 2017; 7(1): 3568, doi: 10.1038/s41598-017-03362-z, indexed in Pubmed: 28620234.

22. Kallen $A N$, Zhou XB, Xu J, et al. The imprinted $\mathrm{H} 19$ IncRNA antagonizes let-7 microRNAs. Mol Cell. 2013; 52(1): 101-112, doi: 10.1016/j.molcel.2013.08.027, indexed in Pubmed: 24055342.

23. Su Z, Hou XK, Wen QP. Propofol induces apoptosis of epithelial ovarian cancer cells by upregulation of microRNA let-7i expression. Eur J Gynaecol Oncol. 2014; 35(6): 688-691, indexed in Pubmed: 25556276.

24. Yang N, Kaur S, Volinia S, et al. MicroRNA microarray identifies Let-7 as a novel biomarker and therapeutic target in human epithelial ovarian cancer. Cancer Res. 2008; 68(24): 10307-10314, doi: 10.1158/00085472.CAN-08-1954, indexed in Pubmed: 19074899.

25. Zhang EB, Han L, Yin DD, et al. c-Myc-induced, long, noncoding H19 affects cell proliferation and predicts a poor prognosis in patients with gastric cancer. Med Oncol. 2014; 31(5): 914, doi: 10.1007/s12032-0140914-7, indexed in Pubmed: 24671855. 